\title{
Best Practices as Opportunities for Leadership Soft Skills Improvement in Human Resource Management in Bulgarian Tourism Organizations: The Four Season Hotels Example
}

\author{
Dr. Mariya Veleva \\ University of Economics - Varna, Varna, Bulgaria \\ maria.veleva@ue-varna.bg
}

\begin{abstract}
Contemporary leadership requires flexibility and adaptability because of the constant changes in the business environment. The purpose of this study is to discuss best practice example in leadership soft skills for managing human resources in Four Season Hotels, and the opportunities for their implementation in Bulgarian tourism organizations. First, the new leadership approaches and a new understanding of the leadership were outlined. Second, pointed out was the essence of the soft skills concept and its close relation to organizational leadership. The characteristics of human resource management in tourism organizations were described. Four Seasons Hotels good practice example was discussed, reffering the leadership soft skills application in successful tourism companies. Best practice implementation in Bulgarian tourism companies was suggested.
\end{abstract}

Keywords: leadership, soft skills, human resource management, tourism

JEL Code: M12, M54 DOI: https://doi.org/10.36997/IJUSV-ESS/2020.9.3.63

\section{Introduction}

World economy and development, based nowadays on new technologies, has brought new dynamics to the business environment. It requires all participants to systematically develop flexibility, adaptability, and a sense of change, together with a desire to constantly invest in new knowledge and skills. Contemporary organizations operating in the tourism sector need them all, to survive, to be competitive, and to be up to date with the $21^{\text {st }}$ century business requirements. Leading organizations in people management have long appreciated the positive potential of modern management theories, about change management, knowledge management, learning organization, leadership, project management, chaos management, intercultural management, corporate social responsibility, etc. Due to this awareness, on global scale, modern tourism organizations not only strategically plan the management of their human resources for achieving organizational goals, but also strategically plan their management for participating in changes, training programs, and decision-making, through which the leaders can increase their professional effectiveness, motivation, satisfaction, and hence - to increase the competitiveness and vitality of the tourism organization in the long run.

It is clear that people, apart from being the most valuable resource, uniting all others in the organization, it is also a very specific resource that sometimes is difficult to be managed. In the past, it was accepted that it was enough to hire managers with a certain set of technical skills, corresponding to the job tasks that were inherent in the vacancy. At the end of the 20th century, however, it became clear that these so-called solid skills are not enough. It turned out that another type of skills, called soft, are extremely necessary, especially in the tourism sector. They refer to building a stable work relationship with people - the one that is so important in communication and interaction with people. "Soft skills" is a sociological term associated with emotional intelligence and individual abilities to interact with people. These skills include communication, language skills, friendliness and optimism, time management, crisis management, etc. - all skills that characterize interactions with other people. This applies crucially to leadership, because leaders are those who lead, show, explain, and help their people do the job, solve problems, and be efficient at the job place. In fact, in 21st century, there is no position in the tourism organization that does not require mastery of a certain set of soft skills. Therefore, in the last 10-15 years, the number of scientific researches on human resource management, leadership, and soft skills has increased avalanche. In 
parallel, many universities, vocational training centers, public and private job fairs, and Assessment Centers have included leadership soft skills training and human resource management in their curricula.

Given the relevance of the topic, the subject of this study is the soft skills for leadership in tourism organizations. The purpose of the paper is to discuss best practice example in leadership soft skills for managing human resources in Four Season Hotels and to point out opportunities for their implementation in the Bulgarian tourism organizations.

\section{Literature review}

The leadership nature in organizations has been in the research focus of organizational studies since it was proven that people are the most specific organizational resource and they have to be managed intelligently. Leadership appears to have roots in several branches of knowledge, like: social sciences, humanities, management, organizational studies. This turns it into a serious multidisciplinary research field.

The contemporary leadership studies accentuate various topics. The search for new theories provokes scholars and practitioners to create new leadership models and approaches and to measure their effectiveness. Because of the complexity of the leadership, some researchers study its effectiveness (McShane, Glinow, 2005; Gregori-Mina, 2009). As result, five leadership components are defined: competency, behavioral, contingency, transformational, and implicit. On this ground further are shaped five leadership styles that are directly related to the components: contingent, transactional, transformational, and charismatic. The description of McShane and Glinow (2005) is that Fiedler's contingency model sets the fundaments of the contingent leadership because it is the earliest contingency theory of leadership. At the other side, the transactional style supports order and structure, and improves organizational efficiency, while the transformational style leads the organization into a better course of activities. The close correlation between transformational leadership and charismatic behavior creates the fourth leadership style based on it - charismatic style. Gregori-Mina (2009) supports the idea that there are researchers who believe the charismatic leadership is more or less a kind of extension of transformational leadership while other researchers perceive the two leadership styles as different from each other. As McShane and Glinow state (2005, p. 58-59), "Charisma is a personal trait that provides referent power over followers, whereas transformational leadership is a set of behaviors...used to lead the change process". What is more, the authors premise that a leader can be transformational and at the same time not to be charismatic.

Recent publications continue to keep research focus on leadership and leaders' effectiveness. Surji (2015) states that from one side, the studies of the leader and leadership tend to seem already too complicated, and at the other side, the researchers reached to a complexity that brings more confusion than understanding of the subject. This demotivates managers and makes the learning process difficult for them. Discussing Maxwell's 5-Ps of leadership, Surji (2015) points out that managers can not become effective leaders unless they go through the five phases in a certain order that should not be changed:
1.Position
2. Permission
3. Production
4. People development
5. Respect

The specific characteristic of human behavior related to group behavior is, that if there is no leader in the group, people soon start to argue and create conflicts. The reason is their different perception - they see things in different ways and lean toward different solutions (Mills, 2005). Leadership in organizations helps to solve this interactional problem and leads people to go in the same direction and put together their efforts so that their performance becomes effective.

To understand better the complicated and vulnerable structure of effective leadership, the 
essence of the soft skills and the synergy between them and leadership should be outlined.

To ensure the ethical side of the leadership, Gregori-Mina (2009) points out that the contemporary leaders should be socio-centric rather than self-centric, otherwise there will be a threat for them to be dethroned. In this case, being socio-centric for a leader means having a high level of emotional intelligence: to be more people-oriented, to be able to understand their feelings, motivation, expectations, way of thinking, decisions, behavior. Having in mind that humans are social creatures and constantly are in interactions with others, soft skills appear to be crucial for the effective communication, effective group behavior, and effective leadership in organizations.

Recently, the concept of soft skills is developed as an inseparable part of the study of jobrelated skills. However, the first one to notice that there are existing other than technical skills is John Dewey (Narayan, 2016). In 1909, while he was developing the idea of social and political philosophy, he defined the term "social intelligence". However, at that time it went unnoticed. Thorndike developed further the idea of intelligence, and specified that social intelligence enables a person to judge and manage their events, emotions, and behavior, as well as the events, emotions and behavior of other individuals and react to them (Meeks, 2007). The study of social intelligence helped the definition of emotional intelligence to be formulated by Salovey and Meyer (Salovey, Mayer 1990; Salovey, Mayer 1993). However, Daniel Goleman (Goleman, 1996) was the first one who linked the theory of emotional intelligence with the management of people in the organization and the effectiveness of their job performance. He claimed that IQ alone can provide only $25 \%$ per employee to be effective in the workplace. The remaining $75 \%$ is depending on his emotional intelligence: the ability to connect with others and to understand oneself and others (Goleman 1998). IQ alone is not able to determine who will succeed or fail. To be successful in their work, people must have the ability to interact positively with colleagues and clients, as well as to analyze different types of information to be able to make decisions appropriate to the work situation. That is why emotional intelligence subsequently acquires such great importance in clarifying the essence of soft skills.

In the search for a modern definition of skills for working with people and why they are called soft skills, opinions are expressed not only by researchers but also practitioners, the latter even registering much more active participation in the process. We can assume that this is because these skills are accepted by social and industrial and organizational psychology as a key to managing people in organizations. In this regard, Coates (Coates 2004) - blogger, PhD in Economics, CEO, consultant, and author of electronic products in the field of HRM, distinguishes between soft and hard skills, defining hard skills as technical or administrative procedures related to the basic activity of the organization. These can be: work with machines, computer programs, occupational safety standards, financial procedures, sales administration. These skills are usually easy to observe and measure. Also, they are easy to learn, as most of the time the hard skills are completely new to the learner and there is no need to first "erase" previous outdated knowledge. On the other hand, "soft skills" (also called "human skills") are usually difficult to observe and quantify. Skills for working with people are necessary both for everyday life and for work. They have to do with how people treat each other: communicate, listen, engage in dialogue, give feedback, collaborate, solve problems, resolve conflicts. The effectiveness of people management largely depends on the skills of those who lead them - how they organize and lead the team, how they stimulate the participation of their employees in meetings, whether they encourage innovation, how to solve work and interpersonal problems and make decisions, how to plan, delegate, monitor, instruct, encourage and motivate.

Many studies (Roehl, Swerdlow, 1999; Quang 2006; Seetha, 2014) show that when hired, people come into the organization with already established interpersonal patterns of behavior that have been learned through various life challenges they have gone through. Besides, Meeks (2007) notes that patterns of human behavior from an early age are established by observing how others do things, experiment, and assimilate what they believe is beneficial. For this reason, leadership is a 
challenge for managers, because in a team it is necessary to adopt different patterns of behavior of different people, who must work together to achieve common goals and performing common tasks.

Outlining the specific characteristics of managing human resources in tourism organizations helps to understand the need for leadership soft skills in this industry. The management of organizations is inextricably linked with the management of the people in it because they are the resource that connects all other resources and contributes to their effective use to achieve organizational goals. At the same time, the dynamic changes in the external environment cause the need for intelligent change management in the internal organizational environment to ensure stability, growth, and competitiveness in organizations (Yancheva, 2017; Kazandzhieva, Lukanova, Santana, 2019; Lukanova, Filipova, 2019). It is these constant changes imposed by the external environment that requires a change in human resource management - it is gaining new dimensions by constantly enriching and updating management techniques (Koleva, 2011). The rapid development of technology also creates an acceleration of changes in organizational management (Marinov, Yancheva, Dyankov, 2019), and managers should be able to lead employees. The tourism industry is no exception - tourism organizations in Bulgaria have to adapt to change, although this sometimes happens with varying degrees of success (Veleva, 2018). In these conditions, leadership in tourism organizations seems to be crucial for organizational success.

Bhanot (2009) points out that an increasing number of companies, to gain a competitive advantage, need to make sure that their people can do their job, know how to treat customers, business partners, and colleagues. Showing empathy, knowing the peculiarities of human behavior, positivism in relationships with people, awareness of how others act and why are just a few of the mandatory competencies necessary for the operation of any progressive organization. They and others like, fall within the perimeter of the soft skills.

It is considered that for organizations operating in the field of services (and in particular tourism) it is of particular importance to build and develop soft skills in the following areas (Bhanot 2009):

- Personal reliability (how much can be relied on the employee/manager in the performance of work tasks);

- Degree of cooperation with others;

- Interpersonal negotiation skills;

- Conflict resolution;

- Adaptation skills and flexibility to change;

- Communication skills;

- Empathy and involvement in common tasks;

- Training and mentoring.

The more of these skills can be established in an organization, the more they have a positive impact on the attitudes, and relationships that people in the organization establish with colleagues, customers, managers, shareholders and others. The more positive attitudes a person has towards others, the better relationships they build with customers (Dabeva, Lukanova, Filipova, 2016). This is also what strengthens teamwork and makes people contribute to organizational success. For this reason, an important commitment in human resource management in tourism organizations is the creation and maintenance of an organizational culture that builds a positive leadership and stimulates employees' active participation in work activities. Tourism organizations should not expect leaders automatically to build teams and lead them, or already to know how to behave in difficult situations and motivate colleagues and subordinates (Binsaeed, Unnisa, Risvi, 2017). It should not be taken for granted if leaders can understand the importance of clear communication, friendship, empathy, and how to create satisfied customers. Leadership soft skills should be permanently set into the managerial training programs' focus.

On the basis of the literature review, it could be suggested, that soft skills are mandatory skills for the leaders and the human resource management in tourism organizations because they 
help them build positive work relations with people. People at work, just like in society, are social creatures, and any lack of leadership soft skills, therefore could generate communicational and interactional problems, conflicts, stress, job dissatisfaction, and demotivation among them. These are all negative aspects of organizational culture that effective organizations avoid by building strong and positive leadership by improving the leadership soft skills of their managers.

\section{Methodology of the research}

For this study the intrinsic best practice example was chosen for the uniqueness of the case studies from the tourism practice included in the research. The position the authors take in this paper is that the best practice examples of leadership soft skills application are an essential component to support and outline the opportunities for their implementation in the Bulgarian tourism organizations.

The authors consider the best practices examples presented in this research to be kind of facility case studies, where the primary thrust is:

1) to capture and document facility information about leadership soft skills application in successful tourism organizations;

2) to understand current trends in leadership soft skills application in leading tourism organizations, as well as the Design Excellence in the tourism organization; and

3) to identify the most important leadership soft skills, that can be suggested for further studies as indicators for the assessment of the level of development of the soft skills for leadership in the Bulgarian tourism organizations.

Leadership best practices in human resource management in Four Seasons Hotels are considered here to be high performing facilities that employ "evidence-based" design and operational approaches. Authors hope that the best practice example given here can be successfully replicated in the Bulgarian tourism practice for human resource management, and especially developing and building up the right organizational values that will stimulate the application of the most needed leadership soft skills. The expectation that their application can achieve similar results in leadership soft skills in the Bulgarian tourism organizations is important because this way the leadership effectiveness could be improved.

The available resources (from the internet) to support the investigation are limited as the research includes off-site investigations only.

The collected data is gathered from the official web-site: an interview with the CEO of Four Seasons Hotels.

On the base of the literature review, the presence of a few leadership characteristics, related closely to the soft skills will be observed:

- Empathy;

- Listening;

- Conflict management;

- Gaining respect;

- Ability to motivate others to do the job;

- Decision making;

- Team management;

- Empowerment

Good practices are used as a Gold Standard (benchmarking). About this, it is assumed that SWOT analysis should not highlight weaknesses and threats. This will be done to strengthen the practical and applied aspect of the leadership soft skills development, as well as to facilitate the managers of the tourism organizations in adapting the example of good leadership practice to help their managerial decisions. 


\title{
discussion
}

3. Best practice in leadership soft skills application in Four Season Hotel: example and

\author{
The Golden Rule: Four Seasons Hotels \\ (adapted from a Forbes publication, dated 17.08.2015)
}

Four Seasons has one of the lowest turnover rates in the industry - the company has been ranked in the "100 best jobs" for 18 years. If Four Seasons they want them to perform at this high level, they must be sure that they will give them what employees need. To do this, the managers asked themselves: what do these employees need to be inspired and to treat their customers in this way? Then they created the Golden Rule: to treat people with the dignity and respect to which they are entitled, creating a work environment that makes everyone express themselves in their best light, creating a team spirit where everyone recognizes their special role.

When in Four Seasons they first set out to determine how they would behave in line with their new corporate commitment to the Golden Rule, there appeared serious problems with some leaders. There were people from the highest level of the company who refused to follow it. Even the CEO had a very difficult time because he knew that if these senior officials did not take the rule at heart, the company would have to part with them. Which they did in the end. Many of their old managers were fired because they did not agree to treat people positively and with respect and did not accept the new corporate philosophy. It takes years of hard work to create a team that is consistent in its values, believes in corporate philosophy, and is willing to do its job following ethical behavior. This is not something that can be achieved by placing a poster or billboard. It cost Four Seasons for about 15 years of work. Today, with a company of over 45,000 people, no one doubts that the Golden Rule is the foundation that has allowed the company to be recognized for the high quality of service that sets them apart from their competitors.

"Leadership" is a term that is misunderstood and sometimes misused: as people move up the career ladder, they somehow inherit the role of "the boss" through promotion. But a boss and a leader are two different things. Senior officials, for example, suddenly may gain power over 40 people in the department and become responsible for them. This caresses their Ego, but does not automatically makes them the leader of these people. Leadership is something that needs to be won every time and only becomes effective if you have earned the trust and respect of the people you are now empowered to lead. Once you gain that respect and trust, only then do you have influence. And it's not because you're their boss, but because you've managed to gain their respect and they believe in you that you can, know and deserve this position. Therefore, when you tell them what you expect from them, they will do the impossible to justify your trust. This is what makes you a leader - this ability to influence not from a position of strength, but a position of respect.

There are now many people who enter this position of "boss" and are not interested in influencing through respect. They do the easiest thing - they use a whip and say, "You have to do this, and you have to get there." At some point, this approach will work: people will work out of obligation, and sometimes out of fear because you are their boss. But that doesn't make you an effective leader. An effective leader makes people jump over themselves, makes everyone want to participate and try to do everything possible to show you, and prove to you that he can. His reward will be your recognition of his achievement because all people have an Ego. We all need to be patted on the shoulder and receive recognition. People naturally seek recognition through the opportunity to show you and prove to you what they can do. The leader's role in this situation is to create a work environment that allows people to express themselves in their best light.

Further, the synthesized short analysis of the strengths and opportunities of this best leadership practice is presented (Table 1). It outlines some specific characteristics of the leadership soft skills applications in Four Seasons hotels: 
Table 1: Strengths and opportunities in the leadership soft skills application for human resource management in hotels "Four Seasons", laid down in their strategy "Golden

Rule"

\begin{tabular}{|c|c|}
\hline STRENGTHS & OPPORTUNITIES \\
\hline $\begin{array}{l}\text { - Creating true leaders that inspire and fascinate } \\
\text { people after them; } \\
\text { - setting up a fair and correct relationship between the } \\
\text { employees and the organization; } \\
\text { - turning people from human resources into capital; } \\
\text { - winning competitive advantage on the labor market; } \\
\text { - creating a positive organizational culture that } \\
\text { develops trust, cooperation, and engagement among }\end{array}$ & $\begin{array}{l}\text { - Maintaining the trust and respect of internal and } \\
\text { external customers for the brand; } \\
\text { - Long-term establishment of a culture of respect and } \\
\text { involvement of people in the organization at all levels; } \\
\text { - Gaining public recognition and respect for the } \\
\text { company; } \\
\text { - Maintaining the leading positions in the industry; } \\
\text { - Increasing competitiveness. }\end{array}$ \\
\hline
\end{tabular}

To establish the strengths and use the opportunities through the "Golden Rule" strategy, we consider that, on the base of the strategy the leaders in Four Seasons Hotels apply leadership soft skills in three different periods:

- At the beginning of the strategy change: conflict management; listening; empathy; ability to motivate the others; team management;

- During the strategy changes: empowerment; listening; empathy; team management; ability to motivate the others;

- After establishing the strategy on all levels: empathy; listening; gaining respect; team management; ability to motivate others.

Concerning the above, it could be assumed that the most applied leadership soft skills, used in all three periods of time, are:

Empathy; Listening; Team management; Ability to motivate the others.

As a result of the short SWOT-analysis of the good practice example of Four Seasons Hotels, several conclusions can be drawn:

- It is clear that ideal tourist organizations do not exist and every organization, although successful, can go through a period of decline in its efficiency;

- Successful tourism organizations are aware of the value of their people and work towards their transformation from human resources into human capital;

- Successful tourism organizations build long-term strategies and policies for improving and developing their human capital;

- Successful tourism organizations organize their internal rules, systems, and procedures so that their focus is on people;

- Focusing on their people, successful tourism organizations create long-term training and development programs to develop their potential and turn them into talents;

- Successful organizations incorporate soft people management skills as an integral element in their organizational culture, in leadership programs, in change management strategies, in strategies for development and improvement of their workforce, in their competitiveness strategies, in their strategies for organizational management, as well as in its strategies for employer brand, social image, etc.

\section{Conclusion}

According to the purpose of the study, the need for a new leadership approaches and new understanding of leadership was outlined. Pointed were the essence of the soft skills concept, as well as its close relation with the leadership in the organizations. The specific characteristics of human resource management in tourism organizations were presented. Four Seasons Hotels good practice example was presented and discussed from the position of the soft skills for leadership in the tourism companies. 
On the base of the results, the authors would suggest a few important managerial leadership solutions, based on the soft skills, to be established in the Bulgarian tourism organizations:

- Setting the main organizational focus on people;

- Building commitment, and re-organization of all management processes;

- Building an appropriate organizational culture that supports, through soft skills, human resource management;

- Establishing effective leadership practices;

- Building commitment and empathy in employees through motivation programs;

- Creating and implementing long-term strategies and programs for employee development;

- Building throughout the whole organization the ability to manage organizational changes.

There exist some limitations: there is a need for wider research so that a comparative analysis to be done. For this purpose, examples of leadership practices in Bulgarian tourism organizations also should be included in a future study.

\section{References}

1. Bhanot, S. (2009), Importance of Soft Skills for an Employee and for the Organization. SIES Journal of Management, April-August, Vol.6(1):18-22.

2. Binsaeed, R., Unnisa, S., Risvi, L. (2017) The big impact of soft skills in today's workplace. International Journal of Economics, Commerce and Management, UK, Vol. V, Issue 1, 456463. [Online] Available from: http://ijecm.co.uk/wp-content/uploads/2017/01/5123.pdf [Accessed 06/09/2019].

3. Dabeva, T., Lukanova, G., Filipova, H. (2016) Comparative analysis of cultural characteristics of Bulgaria and Greece according to Hofstede's paradigm. Cultural corridor Western transbalkan road: Cultural tourism without boundaries, International scientific conference, Meteora-Lefkada, Greece, 29.09 - 03.10, YUZU - Blagoevgrad, 1-13.

4. Four Seasons Hotels: a Forbes publication. [Online] Available from: https://www.forbes.com/sites/micahsolomon/2015/08/17/four-seasons-leader-isadore-sharptreat-employees-right-so-they-treat-customers-right/\#1fb8229c3303 [Accessed 21/05/2020]

5. Goleman, D. (1996) Emotional Intelligence: Why It Can Matter More Than IQ. Bloomsbury Publishing, London.

6. Goleman. D. (1998). Working with emotional intelligence. New York, NY: Bantam Books.

7. Gregory-Mina, H. (2009) Four Leadership Theories Addressing Contemporary Leadership Issues as the Theories Relate to the Scholarship, Practice, and Leadership Model. Academic Leadership: The Online Journal, Vol.7, Issue. 3, Article 10. Available at: https://scholars.fhsu.edu/alj/vol7/iss3/10 [Accessed 04/11/2020].

8. Kazandzhieva, V., Lukanova, G., Santana, H. (2019) Challenges for Technological Innovations Implementation in the Bulgarian Hotels. Society and Sustainable Development : International Conference Information, 6th Edition, May 10 - 11, Targu-Jiu, Romania: Academica Brancusi Publ. House, 133 - 137.

9. Koleva, V. (2011) Kadrovi predizvikatelstva pred IT firmite i ikonomikata na znanieto, v konteksta na novite realnosti. International conference "Interaction theory - practice: key problems and solutions”, 24-25 June. Burgas: Burgas Free University, Vol. 1, 401-408.

10. Lukanova, G., Filipova, H. (2019) Factors Influencing the Timeshare's Application in the Hotel Product of the Bulgarian Black Sea Coast. Strategic Management, XV International Conference on Strategic Management, IMCSM 19, Bor, Sebia, May, 24 - 26, Belgrade : University of Belgrade. Technical Faculty in Bor, 432 - 442.

11. Marinov, S., Yancheva, K., Dyankov, T. (2019) Destination Bulgaria on the Silk Road Opportunities and Challenges. Izvestia Journal of the Union of Scientists - Varna, Economic Sciences Series, 8, (3), 81 - 90. 
12. McShane, S., Glinow, M. (2005) Organizational behavior: Emerging realities for the workplace revolution (3rd ed.). New York: The McGraw-Hill Companies.

13. Meeks, G. (2007) Critical Soft Skills to Achieve Success in the Workplace. Walden Dissertations and Doctoral Studies Collection. [Online] Available from: https://scholarworks.waldenu.edu/dissertations [Accessed 25/03/2020].

14. Mills, Q. (2005) The Importance of Leadership: How to Lead, How to Live. MindEdge Press. [Online] Available from: https://www.amazon.com/Leadership-How-Lead-Live-ebook/dp/ B00B14OHWG [Accessed 03/11/2020].

15. Narayan, J. (2016) Social Intelligence and Equality. Manchester University Press, Series: Theory for a Global Series: Theory for a Global Age. [Online] Available from: https://www.manchesteropenhive.com/view/9781526101020/9781526101020.00010.xml [Accessed 17/02/2020].

16. People Skills: the blog of Coates [Online]. Available from: https://www.2020insight.net/ PeopleSkills.htm [Accessed 17/05/2020].

17. Quang, Q. (2006) Communication Across Cultures. Tap chi Khoa hoc DHQGHN, Ngoai ngu, T XXII, So 4, Doctoral dissertation. [Online] Available from: https://www.researchgate.net/ publication/277199270 [Accessed: 22/03/2020].

18. Roehl, W., Swerdlow , S. (1999) Training and its impact on organizational commitment among lodging employees . Journal of Hospitality and Tourism Research 23 : 176 - 194 .

19. Seetha, N. (2014). Are soft skills important in the Workplace? - A Preliminary Investigation in Malaysia. International Journal of Academic Research in Business and Social Sciences, April, Vol. 4, No. 4, 44-56. [Online] Available from: http://hrmars.com/index.php/papers/detail/ IJARBSS/751 [Accessed: 18/04/2020].

20. Surji, K. (2015) Understanding Leadership and Factors that Influence Leaders' Effectiveness. European Journal of Business and Management, Vol.7, No.33, 154 - 167.

21. Veleva, M. (2018) Upravlenie na promenite v turisticheskite organizacii chrez promyana na naglasite na sluzhitelite. Izvestia Journal of the Union of Scientists - Varna, Economic Sciences Series, Vol. 7 (1), 230-239.

22. Yancheva, K. (2017) Exploring the applications of ancient and modern recreational methods in spa and wellness tourism. Contemporary Tourism - Traditions and Innovations, 19 - 21 October 2017, Sofia, St. Kliment Ohridski University Press, 426 - 443. 